\title{
Elucidating alkane adsorption in sodium-exchanged zeolites from molecular simulations to empirical equations
}

\author{
E. García-Pérez ${ }^{\text {a }}$, I.M. Torréns ${ }^{\text {a }}$, S. Lago ${ }^{\text {a }}$, D. Dubbeldam ${ }^{\text {b }}$, T.J.H. Vlugt ${ }^{c}$, \\ T.L.M. Maesen ${ }^{\text {d, B. Smit }}{ }^{\text {, }}$ R. Krishna ${ }^{\text {b }}$, S. Calero ${ }^{\text {a,* }}$ \\ ${ }^{a}$ Department of Environmental Sciences, University Pablo de Olavide, Ctra. Utrera km 1, 41013 Sevilla, Spain \\ ${ }^{\mathrm{b}}$ Department of Chemical Engineering, University of Amsterdam, Nieuwe Achtergracht 166, 1018 WV Amsterdam, The Netherlands \\ ${ }^{\mathrm{c}}$ Condensed Matter and Interfaces, Debye Institute, Utrecht University, P.O. Box 80.000, 3508 TA Utrecht, The Netherlands \\ ${ }^{\mathrm{d}}$ ChevronTexaco, Energy Technology Company, Chevron Way 100, Richmond, CA 94802-0627, USA
}

Available online 11 May 2005

\begin{abstract}
Configurational-bias Monte Carlo (CBMC) simulations provide adsorption isotherms, Henry coefficients and heats of adsorption of linear alkanes in sodium-exchanged MFI- and FAU-type zeolites. These simulations were carried out using our newly developed force field that reproduces experimental sodium positions in the dehydrated zeolites, and successfully predicts alkane adsorption properties over a wide range of sodium cation densities, temperatures, and pressures. We derived empirical expressions from the simulation data to describe the adsorption of linear alkanes in MFI- and FAU-type zeolites. These expressions afford a suitable substitute for complex CBMC simulations. In the low coverage regime we provide simple expressions that adequately describe the Henry coefficient and adsorption enthalpy of $n$-alkanes as a function of sodium density and temperature. The predicted Henry coefficients and heats of adsorption compare extremely well to available experimental data. In the high coverage regime we provide an expression for saturation capacities of linear alkanes in the zeolite. This expression, combined with the expression for the Henry coefficients, provides of the complete adsorption isotherms of pure adsorbents and mixtures, in good agreement with the adsorption isotherms obtained from CBMC.
\end{abstract}

(C) 2005 Elsevier B.V. All rights reserved.

Keywords: Molecular simulations; Empirical equations; CBMC

\section{Introduction}

Zeolites are microporous materials with widespread use in several areas of technology. They yield efficient heterogeneous catalysts, adsorbents, and gas

\footnotetext{
* Corresponding author.

E-mail address: scaldia@dex.upo.es (S. Calero).
}

separators [1-4]. Molecular simulations are a powerful tool for gaining insight into the physics underlying the widespread use of zeolites in these industrial processes at a molecular level. In particular, configurational-bias Monte Carlo (CBMC) simulations are capable of accurately predicting adsorption isotherms of linear and branched alkanes [5-9] and their mixtures $[10,11]$ in zeolites. 
Among the numerous synthetic zeolites known to date, zeolites with FAU and MFI topologies are the most widely studied and the most commercially important [12-18]. The FAU-type zeolite topology consists of small (sodalite) cages arranged so as to form $1.2 \mathrm{~nm}$ wide supercages accessible through $0.72 \mathrm{~nm}$ wide windows. The composition of the unit cell is $\mathrm{Na}_{x} \mathrm{Al}_{x} \mathrm{Si}_{192-x} \mathrm{O}_{384}$, where $96 \geq x \geq 0$. FAUtype zeolites are called either $X$ and $Y$-depending on their framework aluminium density $(x) . X$ has a framework aluminium density between 96 and 77 aluminium atoms per unit cell, whereas $Y$ contains fewer than 77 framework aluminium atoms per unit cell. The MFI-type zeolite can be synthesized with a composition range $8 \leq \mathrm{Si} / \mathrm{Al} \leq \infty$. It is a threedimensional pore system consisting of straight, $0.53 \mathrm{~nm}$ across parallel channels intersected by perpendicular zigzag channels. At room temperature the composition of the unit cell is $\mathrm{Na}_{x} \mathrm{Al}_{x} \mathrm{Si}_{96-x} \mathrm{O}_{192}$, where $27 \geq x \geq 0$ [19]. MFI-type zeolites are called either ZSM-5 or silicalite depending on the framework aluminium density $(x)$. The name silicalite is used for zeolites with a very low $x$ value.

The remainder of the paper is organized as follows: in Section 2 we present our simulation methods. We continue in Section 3 with the results of our simulations. These include adsorption isotherms, Henry coefficients and heats of adsorption of linear alkanes in several MFI and FAU structures varying the non-framework sodium concentration. We fit the results with an empirical expression for Henry coefficients and heats of adsorption as a function of the sodium concentration, temperature, and linear alkane, and we extend our calculations to mixtures of alkanes at high pressure. Finally, we give some concluding remarks in Section 4.

\section{Methodology}

Simulations in the low and high coverage regime were computed using configurational-bias Monte Carlo simulation in the grand-canonical ensemble (constant chemical potential, constant volume $V$, and constant temperature $T$ ) and $N V T$ ensemble (constant number of particles $N$, constant volume $V$, and constant temperature $T$ ), respectively. The conventional simulation techniques to compute adsorption isotherms are prohibitively expensive for long alkanes whereas the CBMC technique simulates them at affordable cost [20]. In a CBMC simulation molecules are grown bead by bead biasing the growth process towards energetically favorable configurations avoiding overlap with the zeolite. During the growth the Rosenbluth factor is calculated. The average Rosenbluth factor is directly related to the free energy and the Henry coefficient $[21,22]$. More details on this simulation technique can be found elsewhere [21,23,24].

Zeolite frameworks have been constructed from silicon, aluminium, and oxygen atoms. FAU-type zeolite were modeled utilizing the crystallographic atom positions in dehydrated $\mathrm{Na}-X$ [25]. The structures with lower framework aluminium densities were obtained by randomly substituting aluminium by silicon. This procedure automatically satisfies the Löwenstein rule and it should afford a reasonable approximation of the framework aluminium distributions obtained by experimental methods [26-29]. The MFI-type zeolites were modeled from the crystallographic structure of silicalite of van Koningsveld et al. [30] in which Si atoms were substituted by $\mathrm{Al}$ atoms at the preferred positions as indicated by Stave and Nicholas [31] and AlvaradoSwaisgood et al. [32]. In all cases the simulation boxes were chosen large enough to obey the minimum image convention with a potential cutoff of $12 \AA$ and periodic boundary conditions were applied in all directions. The charge distribution on the oxygen framework was considered static, i.e. polarization of oxygen by nearby sodium cations is implicitly modeled by distinguishing silicon from aluminium with a difference of $0.3 \mathrm{e}^{-}$between $q_{\mathrm{Si}}$ and $q_{\mathrm{Al}}$ [33]. Different charges are used for oxygen atoms bridging two silicon atoms, $q_{\mathrm{OSi}}$, and oxygen atoms bridging one silicon and one aluminium atom $q_{\mathrm{OAl}} \cdot q_{\mathrm{OSi}}$ is obtained using the relation $q_{\mathrm{Si}}+(2 x$ $\left.q_{\mathrm{OSi}}\right)=0$, making the zeolite neutral in the absence of aluminium, while $q_{\mathrm{OAl}}$ is chosen to make the total system charge equal to zero [34-36].

The non-framework sodium cation density was adjusted to match the framework aluminium density and the density of the zeolites is determined by the framework atoms (aluminium, silicon and oxygen) and the non-framework cations (sodium). In our model, the sodium cations can move freely and adjust their position depending on their interactions with the 
framework atoms, other sodium cations, and alkane molecules.

The interactions between guest molecules (alkanes and sodium cations) with the zeolite host framework are modeled by Lennard-Jones and Coulombic potentials. The Coulomb interactions in the system are calculated using the Ewald summation [21]. The alkanes are described with a united atom model, in which $\mathrm{CH}_{x}$ groups are considered as a single interaction centers with their own effective potentials [37]. The beads in the chain are connected by harmonic bonding potentials. The bond bending between three neighbouring beads is modeled by a harmonic cosine bending potential and changes in the torsional angle are controlled by a Ryckaert-Bellemans potential. The beads in a chain separated by more than three bonds interact with each other through a Lennard-Jones potential. The interactions of the adsorbed molecules with the zeolite are dominated by the dispersive forces between the pseudo-atoms and the oxygen atoms of the zeolite $[23,38,39]$ meaning that the silicon van der Waals interactions are taken into account through an effective potential with only the oxygen atoms. We use a newly developed force field, where the nature, density, and mobility of the non-framework cation, the density of the framework aluminium, and all hostguest interactions are carefully taking into account. The alkane-sodium, alkane-alkane, and alkanezeolite interaction parameters were obtained by calibrating the force field through explicitly fitting a full isotherm over a wide range of pressures, temperatures and sodium densities [36]. We fit complete adsorption isotherms, because experimental determination of the adsorption properties at very low and at very high coverage is fraught with difficulty resulting in a large spread in experimentally determined Henry coefficients and saturation loadings, respectively. The agreement between experimental data from different groups in the intermediate coverage regime is significantly better [36].

\section{Results and discussion}

In our previous work, we presented a new force field able to reproduce accurately all adsorption properties in sodium-exchanged faujasite zeolites [36]. The following results demonstrate that this force field can be

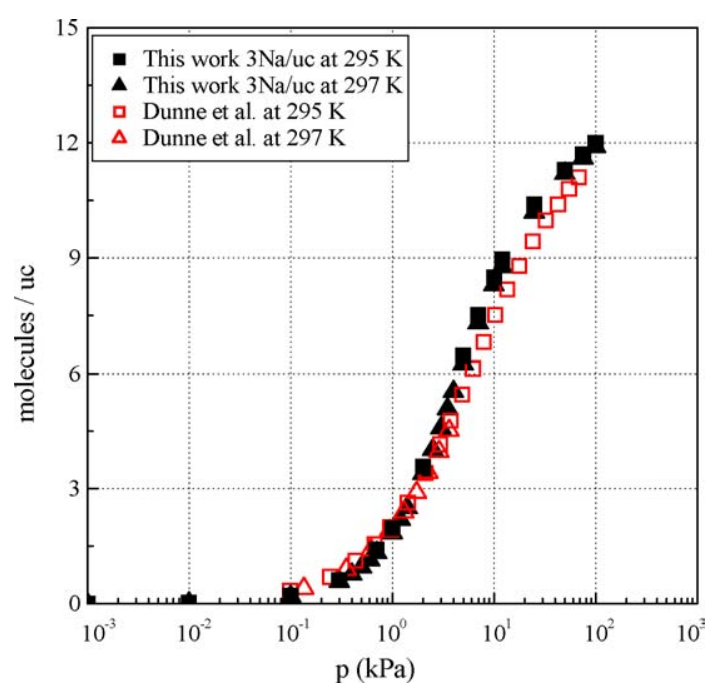

Fig. 1. Adsorption isotherms of ethane in sodium-exchanged MFI obtained from our CBMC simulation. Experimental isotherms are included for comparison [40].

successfully extended to sodium-exchanged MFI-type zeolites. Fig. 1 shows the excellent agreement of our computed isotherms for ethane with available experimental data [40]. The number of sodium cations and the temperature used for each isotherm were chosen to facilitate comparison with these experimental data. Hence, the ethane isotherms in Fig. 1 were obtained for MFI structures with $3 \mathrm{Na}^{+} / \mathrm{uc}$ at 295 and $297 \mathrm{~K}$, respectively. It is important to note (1) that the data obtained for MFI structures were not part of the calibration of validation data and (2) that our computed isotherms reproduce the experimental isotherm shape and also the experimental saturation capacity of the validation data set.

Henry coefficients and heats of adsorption of linear alkanes were computed for a wide range of temperatures and the full range of aluminium (and sodium) densities in both FAU- and MFI-type zeolites. Fig. 2a and b show the obtained Henry coefficients as a function of the sodium density for the faujasite $(500 \mathrm{~K})$ and MFI $(300 \mathrm{~K})$ structures, respectively. These values adequately fit on a surface defined through the expression:

$\ln K_{\mathrm{H}}=\left(\eta N_{\mathrm{s}}+v\right) \mathrm{CN}-\xi$

where $\eta, v$, and $\xi$ are given in Table 1 for a wide range of temperatures. This temperature dependence is captured by a relationship with three sets of $x_{1}\left(K^{2}\right)$, 

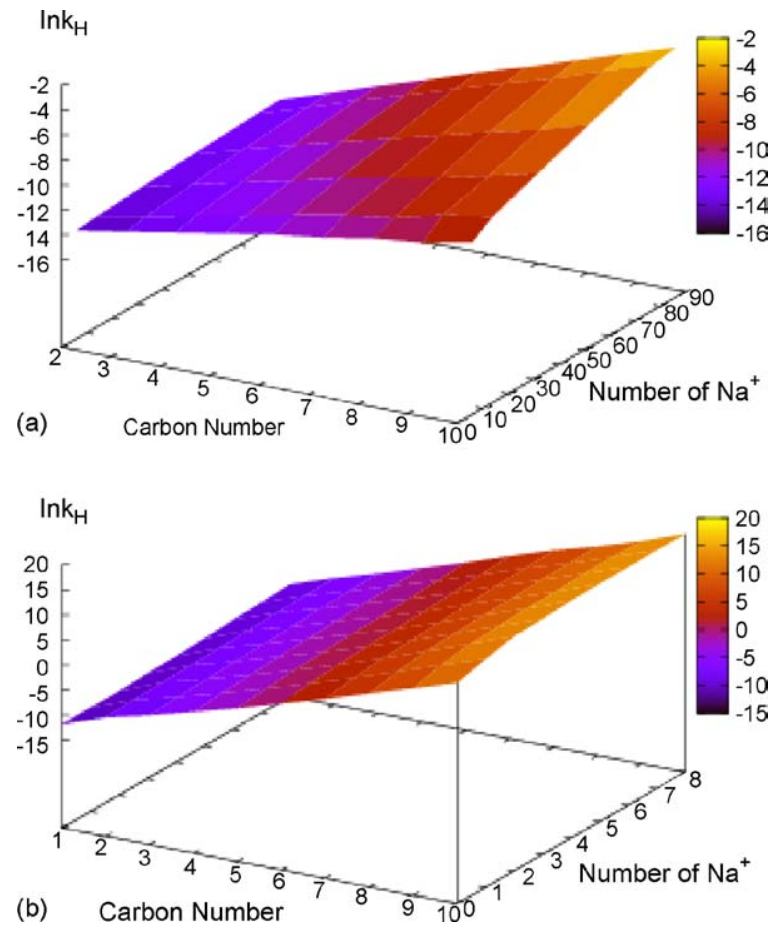

Fig. 2. The Henry coefficients of $n$-alkanes as a function of the number of sodium cations fit nicely to a surface: (a) Na-FAU at $500 \mathrm{~K}$; (b) Na-MFI at $300 \mathrm{~K}$.

Table 1

Coefficients $\eta, v$, and $\xi$ as a function of the temperature $T$

\begin{tabular}{clll}
\hline$T(\mathrm{~K})$ & $\eta$ & $v$ & $\xi$ \\
\hline Na-FAU & & & \\
298 & 0.014957 & 1.39119 & 14.4646 \\
350 & 0.012264 & 1.08779 & 14.866 \\
400 & 0.010578 & 0.876027 & 15.1529 \\
450 & 0.009006 & 0.73277 & 15.4171 \\
500 & 0.007988 & 0.605648 & 15.6199 \\
550 & 0.00708 & 0.504509 & 15.7754 \\
600 & 0.006323 & 0.42539 & 15.9129 \\
650 & 0.005722 & 0.358542 & 16.0439 \\
Na-MFI & & & \\
250 & 0.074 & 342.42 & 130.20 \\
300 & 0.048 & 26008 & 139.60 \\
350 & 0.035 & 200.81 & 145.25 \\
400 & 0.024 & 157.08 & 149.24 \\
450 & 0.017 & 123.35 & 152.52 \\
500 & 0.011 & 0.97 & 155.19 \\
\hline
\end{tabular}

These values were obtained by fitting the Henry coefficients obtained for linear alkanes in sodium-exchanged MFI- and FAUtype zeolites to the surfaces reproduced by Eq. (1).
Table 2

Coefficients used in Eqs. (3)-(5) for sodium-exchanged MFI- and FAU- type zeolites

\begin{tabular}{|c|c|c|c|c|c|}
\hline & \multicolumn{2}{|c|}{$a_{1}$} & \multicolumn{2}{|l|}{$a_{2}$} & $a_{3}$ \\
\hline MFI & \multicolumn{2}{|c|}{4387.72} & \multicolumn{2}{|l|}{5} & -0.016 \\
\hline \multirow[t]{2}{*}{ FAU } & & & 4.37 & & -0.00135 \\
\hline & \multicolumn{2}{|c|}{$b_{1}$} & \multicolumn{2}{|l|}{$b_{2}$} & $b_{3}$ \\
\hline MFI & \multicolumn{2}{|c|}{10570} & \multicolumn{2}{|l|}{1166.4} & -1.409 \\
\hline \multirow[t]{2}{*}{ FAU } & \multicolumn{2}{|c|}{27438.4} & \multicolumn{2}{|l|}{432.8} & -0.3716 \\
\hline & \multicolumn{2}{|c|}{$c_{1}$} & \multicolumn{2}{|l|}{$c_{2}$} & $c_{3}$ \\
\hline MFI & & & 1221.89 & & -17.9 \\
\hline \multirow[t]{2}{*}{ FAU } & \multicolumn{2}{|c|}{-49567.3} & \multicolumn{2}{|l|}{1111.13} & -17.634 \\
\hline & $D_{1}$ & $D_{2}$ & $D_{3}$ & $E_{1}$ & $E_{2}$ \\
\hline MFI & 1.1 & 21.5 & 6.9 & 2.7 & 13 \\
\hline FAU & 2.6 & 144.9 & 50.6 & 1.7 & 9.3 \\
\hline
\end{tabular}

$x_{2}(K)$, and $x_{3}$ defining the value of $\eta, v$, and $\xi$ as a function of temperature.

$z(T)=\frac{\left(\left(x_{1} / T\right)+x_{2}\right)}{T}+x_{3}, \quad z=\eta, v, \xi$

Finally, Eqs. (1) and (2) can be combined into an empirical expression that describes the $n$-alkane Henry coefficient $K_{\mathrm{H}}\left(\mathrm{mol} \mathrm{kg}{ }^{-1} \mathrm{~Pa}^{-1}\right)$ as a function of sodium density $N_{\mathrm{s}}$ (cations per unit cell), the temperature $T(\mathrm{~K})$, and the carbon number $\mathrm{CN}$ :

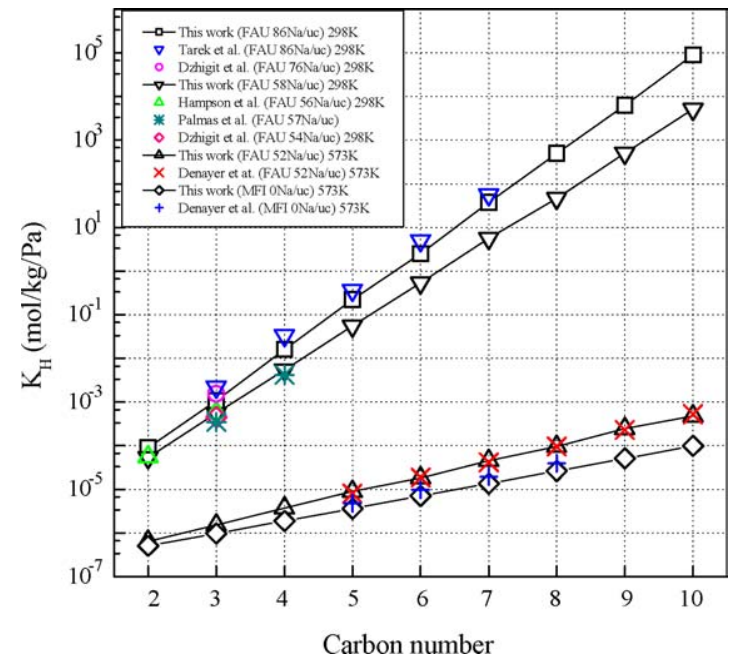

Fig. 3. Henry coefficients of linear alkanes in sodium faujasites and MFI at several temperatures obtained from our empirical expression. In all cases deviation between our empirical Eq. (3) and computed results is smaller than the symbol size. Available experimental and simulation sets are included for comparison [41-46]. 


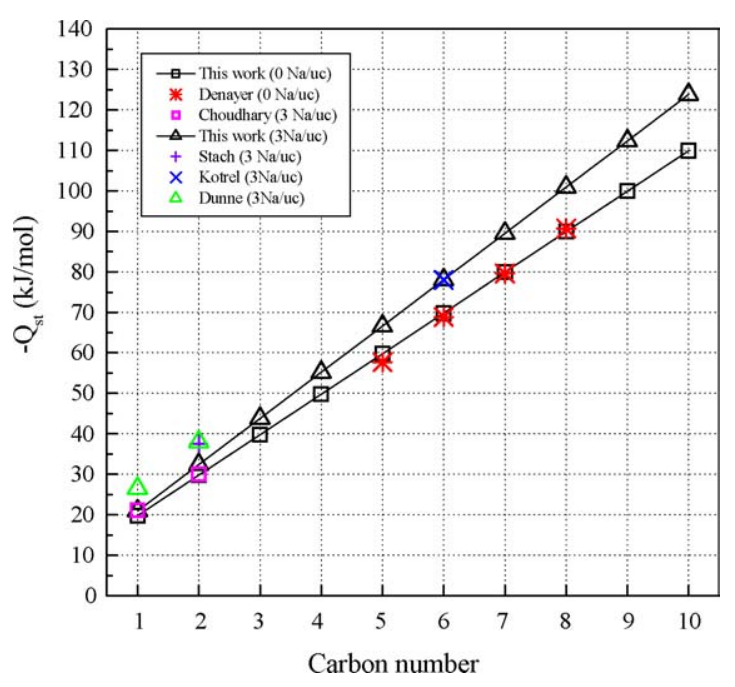

Fig. 4. Heats of adsorption of linear alkanes in Na-MFI zeolites obtained from our empirical expression. In all cases deviation between our empirical Eq. (4) and the computed results is smaller than the symbol size. Available experimental and simulation sets are included for comparison [47-51].

$$
\begin{aligned}
\ln K_{\mathrm{H}}= & \frac{1}{T^{2}}\left[\left(a_{1} N_{\mathrm{s}}+b_{1}\right) \mathrm{CN}+c_{1}\right] \\
& +\frac{1}{T}\left[\left(a_{2} N_{\mathrm{s}}+b_{2}\right) \mathrm{CN}+c_{2}\right] \\
& +\left(a_{3} N_{\mathrm{s}}+b_{3}\right) \mathrm{CN}+c_{3}
\end{aligned}
$$

where $a_{i}, b_{i}$, and $c_{i}$, are listed in Table 2 for both, FAU and MFI topologies. The temperature derivative of this

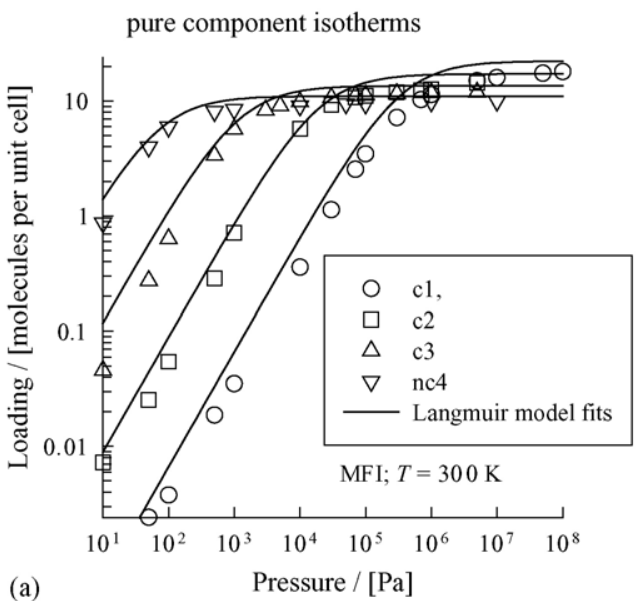

equation provides an expression for the adsorption enthalpy $\Delta H_{0}(\mathrm{~kJ} / \mathrm{mol})$ :

$$
\begin{aligned}
-\Delta H_{0}= & \frac{2}{T}\left[\left(a_{1} N_{\mathrm{s}}+b_{1}\right) \mathrm{CN}+c_{1}\right] \\
& +\left(a_{2} N_{\mathrm{s}}+b_{2}\right) \mathrm{CN}+c_{2}
\end{aligned}
$$

Not that these expressions can be applied independently of the zeolite topology. Fig. 3 compares the Henry coefficients obtained for $n$-alkanes from this empirical expression with available experimental data in both topologies [41-46]. The calculated heats of adsorption of methane to decane in sodiumexchanged MFI structures are given in Fig. 4. A comparison with available experimental data is included [47-51].

As reported in our previous work [36], the applicability of the new force field is by no means limited to low pressure for it also reproduces accurately the adsorption of alkanes at high pressures. The saturation capacities of $n$-alkanes (methane to hexadecane) were computed for several $\mathrm{Na}$ exchanged MFI. From our simulations we can conclude that (1) saturation capacities $\theta_{\text {sat }}$ (molecules per unit cell) are roughly independent on the amount of sodium non-framework cations and (2) saturation capacities can be fit to a second order exponential decay as a function of the carbon number $(\mathrm{CN})$ for both FAU and MFI topologies:

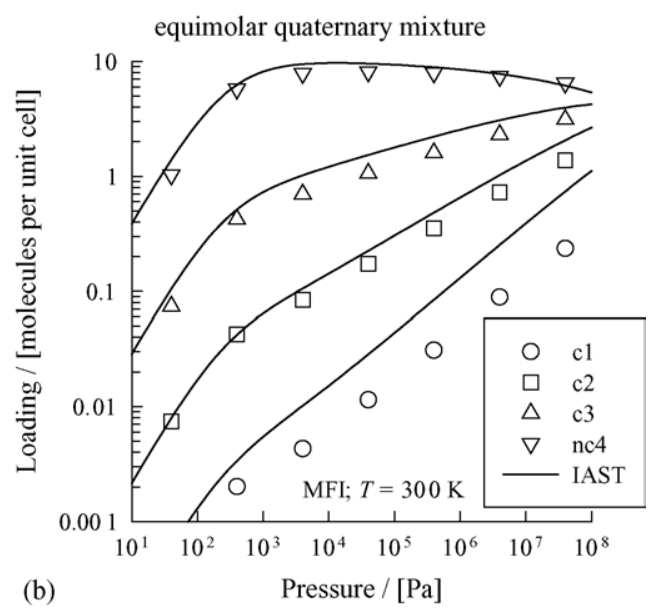

Fig. 5. Adsorption isotherms of $n$-alkanes in MFI using (1) CBMC simulation (symbols), (2) a Langmuir model in which the parameters are calculated from Eqs. (3) and (5) (line) and (3) using the Ideal Adsorbed Solution Theory (IAST). Left: pure components. Right: equimolar mixture of methane, ethane, propane and $n$-butane. 


$$
\begin{aligned}
\theta_{\text {sat }}(\text { molecules } / \mathrm{uc})= & D_{1}+D_{2} \exp -\left[\frac{\mathrm{CN}}{E_{1}}\right] \\
& +D_{3} \exp -\left[\frac{\mathrm{CN}}{E_{2}}\right]
\end{aligned}
$$

$$
\begin{aligned}
& \theta_{\text {sat }}(\text { molecules } / \mathrm{uc}) \\
& \quad=\theta_{\text {sat }}\left(\mathrm{mol} \mathrm{kg}^{-1}\right) N_{\mathrm{AV}} \rho\left(\mathrm{kg} \mathrm{m}^{-3}\right) V\left(\mathrm{~m}^{3}\right)
\end{aligned}
$$

where $N_{\mathrm{AV}}$ is Avogadro's number, $\rho$ the zeolite density, $V$ is the volume of the unit cell and $D_{i}$ and $E_{i}$ are listed in Table 2 . The saturation capacity $\left(\mathrm{mol} \mathrm{kg}^{-1}\right)$ combined with the expression for the Henry coefficients Eq. (3) allow the direct estimation of the adsorption isotherms of linear alkanes in these zeolites. The above correlations for the Henry coefficient and the saturation capacity can be used to obtain a rough estimate of the complete adsorption isotherm, by using the Langmuir isotherm. This can be observed in Fig. 5 for the adsorption of pure component $\mathrm{C} 1, \mathrm{C} 2$, $\mathrm{C} 3$ and $n-\mathrm{C} 4$ and the equimolar quaternary mixture in MFI at $300 \mathrm{~K}$.

\section{Conclusions}

In this work, we have performed molecular simulations to determine adsorption isotherms, Henry coefficients, and heats of adsorption of linear alkanes $\left(\mathrm{C}_{1}-\mathrm{C}_{10}\right)$ in zeolites containing non-framework sodium cations and framework aluminium atoms. Our simulations reproduce accurately the available experimental adsorption data in sodium-exchanged MFI- and FAU-type zeolites over a wide range of cation densities, temperatures, and pressures. Firstly, our simulations predict adsorption properties in the low-pressure regime and from the resulting simulation data we have obtained a simple empirical expression that describes the $n$-alkane Henry coefficient and adsorption enthalpy as a function of sodium density and temperature at low coverage, affording an adequate substitute for complex configurational-bias Monte Carlo simulations. Application of our newly developed force field is by no means limited to FAU topologies, as it successfully reproduces the adsorption properties of alkanes in sodium-exchanged MFI structures.

\section{Acknowledgements}

We would like to thank for financial support the Spanish Ministry of Science and Technology (Ramón y Cajal Program), The Netherlands Research Council for Chemical Sciences (NWO-CW), and Chevron Texaco.

\section{References}

[1] A. Zecchina, C. Otero Areán, Chem. Soc. Rev. 25 (1996) 187.

[2] RA. van Santen, D. Kramer, Chem. Rev. 95 (1995) 637.

[3] M. Schenk, S. Calero, T.L.M. Maesen, L.L. van Benthem, M.G. Verbeek, B. Smit, Angew. Chem.-Int. Ed. 41 (2002) 2500.

[4] M. Schenk, B. Smit, T.J.H. Vlugt, T.L.M. Maesen, Angew. Chem.-Int. Ed. 40 (2001) 736-739.

[5] V. Lachet, A. Boutin, B. Tavitian, AH. Fuchs, Faraday Discuss. (1997) 307-323.

[6] R. Krishna, B. Smit, T.J.H. Vlugt, J. Phys. Chem. A 102 (1998) 7727-7730.

[7] C.F. Mellot, A.K. Cheetham, S. Harms, S. Savitz, R.J. Gorte, A.L. Myers, J. Am. Chem. Soc. 120 (1998) 5788-5792.

[8] M.D. Macedonia, D.D. Moore, E.J. Maginn, Langmuir 16 (2000) 3823-3834.

[9] M. Schenk, S.L. Vidal, T.J.H. Vlugt, B. Smit, R. Krishna, Langmuir 17 (2001) 1558-1570.

[10] S. Calero, B. Smit, R. Krishna, J. Catal. 202 (2001) 395-401.

[11] S. Calero, B. Smit, R. Krishna, Phys. Chem. Chem. Phys. 3 (2001) 4390-4398.

[12] H. Hattori, Heterogeneous basic catalysis, Chem. Rev. 95 (1995) 537-558.

[13] C.N. Satterfield, C.S. Cheng, AIChE J. 18 (1972) 720-723.

[14] D.W. Breck, Zeolite Molecular Sieves, Wiley, New York, 1974 .

[15] J.F.M. Denayer, R.A. Ocakoglu, W. Huybrechts, B. Dejonckheere, P. Jacobs, S. Calero, R. Krishna, B. Smit, G.V. Baron, J.A. Martens, J. Catal. 220 (2003) 66-73.

[16] E.M. Flanigen, J.M. Bennet, J.M. Grose, R.W. Cohen, J.P. Patton, R.L. Kirchen, R.M. Smith, Nature 271 (1978) 512.

[17] D.H. Olson, G.T. Kokotailo, S.L. Lawton, W.M. Meier, J. Phys. Chem. 85 (1981) 2238.

[18] H. van Bekkum, E.M. Flanigen, C. JJ, Studies in Surface Science and Catalysis, vol. 58, Elsevier Science B.V., Amsterdam, 1991.

[19] C. Baerlocher, W.M. Meier, D.H. Olson, Atlas of Zeolite Structure Types, fifth ed., Elsevier, London, 2001.

[20] B. Smit, T.L.M. Maesen, Nature 374 (1995) 42-44.

[21] D. Frenkel, B. Smit, Understanding Molecular Simulations: From Algorithms to Applications, second ed., Academic Press, San Diego, CA, 2002.

[22] D. Dubbeldam, S. Calero, T.L.M. Maesen, B. Smit, Phys. Rev. Lett. 90 (2003) art. no.-245901.

[23] T.J.H. Vlugt, R. Krishna, B. Smit, J. Phys. Chem. B 103 (1999) 1102-1118. 
[24] B. Smit, J.I. Siepmann, J. Phys. Chem. 98 (1994) 8442-8452.

[25] D.H. Olson, Zeolites 15 (1995) 439-443.

[26] M.T. Melchior, D.E.W. Vaughan, A.J. Jacobson, J. Am. Chem. Soc. 104 (1982) 4859-4864

[27] C.P. Herrero, J. Chem. Soc., Faraday Trans. 87 (1991) 2837 2841.

[28] EA. Muller, LF. Rull, LF. Vega, KE. Gubbins, J. Phys. Chem. 100 (1996) 1189-1196.

[29] BK. Peterson, J. Phys. Chem. B 103 (1999) 3145-3150.

[30] H. van Koningsveld, H. van Bekkum, J.J. C, Acta Crystallogr. Sec. B 43 (1987) 127.

[31] M.S. Stave, J.B. Nicholas, J. Phys. Chem.-US 99 (1995) 15046.

[32] A.E. Alvarado-Swaisgood, M.K. Barr, P.J. Hay, A. Redondo, J. Phys. Chem. 95 (1991) 10031.

[33] E. Jaramillo, S.M. Auerbach, New force field for Na cations in faujasite-type zeolites, J. Phys. Chem. B 103 (1999) 9589_ 9594.

[34] E. Beerdsen, B. Smit, S. Calero, J. Phys. Chem. B 106 (2002) 10659-10667.

[35] E. Beerdsen, D. Dubbeldam, B. Smit, T.J.H. Vlugt, S. Calero, J. Phys. Chem. B 107 (2003) 12088-12096.

[36] S. Calero, D. Dubbeldam, R. Krishna, B. Smit, T.J.H. Vlugt, J.F. Denayer, J.A. Martens, T.L.M. Maesen, J. Am. Chem. Soc. 126 (2004) 11377-11386.

[37] J.P. Ryckaert, A. Bellemans, Faraday Discuss. Chem. Soc. 66 (1978) 95.
[38] A.G. Bezus, A.V. Kiselev, A.A. Lopatkin, Q.D. Pham, J. Chem. Soc., Faraday Trans. 2 (74) (1978) 367.

[39] A.V. Kiselev, A.A. Lopatkin, A.A. Shulga, Zeolites 5 (1985) 261.

[40] J.A. Dunne, M. Rao, S. Sircar, R.J. Gorte, A.L. Myers, Langmuir 12 (1996) 5896-5904.

[41] J.F.M. Denayer, G.V. Baron, Adsorpt.-J. Int. Adsorpt. Soc. 3 (1997) 251-265.

[42] M. Tarek, R. Kahn, E.C. Delara, Zeolites 15 (1995) 67-72.

[43] S. Palmas, A.M. Polcaro, R. Carta, G. Tola, J. Chem. Eng. Data 36 (1991) $1-4$.

[44] J.A. Hampson, L.V.C. Pees, Zeolites and microporous crystals 83 (1994) 197-208.

[45] O.M. Dzhigit, A.V. Kiselev, T.A. Rachmanova, J. Chem. Soc., Faraday Trans. 2 (75) (1979) 2662-2677.

[46] O.M. Dzhigit, A.V. Kiselev, T.A. Rachmanova, Zeolites 4 (1984) 389-397.

[47] J.A. Dunne, M. Rao, S. Sircar, R.J. Gorte, A.L. Myers, Langmuir 13 (1997) 4333-4341.

[48] H. Stach, K. Fiedler, J. Janchen, Pure Appl. Chem. 65 (1993) 2193-2200.

[49] S. Kotrel, M.P. Rosynek, J.H. Lunsford, J. Phys. Chem. B 103 (1999) 818-824.

[50] J.F. Denayer, W. Souverijns, P.A. Jacobs, J.A. Martens, G.V. Baron, J. Phys. Chem. B 102 (1998) 4588-4597.

[51] V.R. Choudhary, S. Mayadevi, Sep. Sci. Technol. 28 (1993) 2197. 